\title{
On the Nature of Competition in Alternative Electoral Systems
}

\author{
Matias laryczower Princeton University \\ Andrea Mattozzi EUI and MOVE
}

\begin{abstract}
We link the intensity of campaign competition in different electoral systems with the number of candidates running for public office and their ideological differentiation. We show that proportional elections have more candidates, competing less aggressively in campaign spending, than those in majoritarian elections. Candidates' ideological positions, however, can in general be more differentiated in majoritarian or proportional elections. We also study the equilibrium effects of plurality premiums and the consequences of heterogeneity among candidates in nonideological characteristics.
\end{abstract}

I all elections for major public office positions, ${ }^{1}$ candidates invest a considerable amount of time, effort, and financial resources in persuasive campaigning. ${ }^{2}$ Classic examples include broadcasting TV ads that highlight desirable characteristics of the candidate, publishing and disseminating information aimed at reducing uncertainty about the candidate's platform, or communicating readiness to voters by hiring expert staff and formulating appropriate responses to current events.

In spite of its relevance in modern elections, campaign competition has not been systematically integrated in a theory of elections, together with the number and ideological position of the candidates running for office. This omission could be of no major consequence if the nature of campaign competition were unrelated to other characteristics of the alternatives available to voters. However, this is not the case. The number of candidates running for office, their ideological differentiation, and the intensity of campaign competition are all strategically intertwined.

On the one hand, the farther apart the policy alternatives represented by candidates running for office, the larger is the incentive for a new candidate to run representing an intermediate ideological alternative. On the other hand, the less diverse the

ideological positions represented by candidates running for office, the larger is the number of voters that will be swayed by persuasive campaigning. These features, moreover, are all jointly determined in response to the rules shaping the nature of competition among candidates, and in particular by the electoral system. By affecting how votes cast in elections translate to representation in government-and ultimately how voters' preferences are mapped into policy outcomes-electoral systems shape the characteristics of the alternatives available to voters through the responses they induce in voters and politicians.

In this article, we tackle the effect of alternative electoral systems on the number of candidates running for office, the ideological diversity of their platforms, and the intensity of campaign competition. We focus on a comparison between a pure majoritarian electoral system - in which the winner of a plurality of votes has full control of policy and government-and a pure proportional electoral system, in which the influence of each party is captured by its share of votes in the election. While this stylized representation of alternative electoral systems admittedly simplifies the richness of the diverse array of electoral institutions in use throughout the world, it allows us to

\footnotetext{
${ }^{1}$ Mattozzi acknowledges financial support from the National Science Foundation, SES-0617901 and from Spanish Ministry of Economy and Competitiveness, Grant ECO2011-28822. An online appendix with supplementary material for this article is available at www. journals.cambridge.org/jop.

${ }^{2}$ See for example Coleman and Manna (2000), Erikson and Palfrey (2000), Gerber (1998), Green and Krasno (1988), and Stratmann (2009).
}

The Journal of Politics, Vol. 75, No. 3, July 2013, Pp. 743-756

doi:10.1017/S0022381613000583

(C) Southern Political Science Association, 2013

ISSN 0022-3816 
capture the essence of two major classes of electoral systems. ${ }^{3}$

Our model integrates three different approaches in formal models of elections, allowing free entry of candidates, differentiation in a private value dimension, or ideology, and in a common value dimension, through persuasive campaigning. Each potential candidate is endowed with an ideological position that she can credibly represent if she chooses to run and gets elected. With the field of competitors given, candidates running for office then invest resources in persuasive campaigning, developing (the perception of) an attribute that is valued by all voters alike. We assume that in deciding whether to run for office or not, each potential candidate cares about the spoils she can appropriate from being in office and that voters are fully rational and vote strategically.

The incentives of voters and politicians are shaped by the electoral system under consideration. In majoritarian electoral systems, the candidate who wins a plurality of votes appropriates all rents from office and implements the policy she represents. In proportional electoral systems, all parties obtaining a positive share of the votes participate in government. To reflect this in a simple setting, we assume that in proportional electoral systems the policy outcome is the result of a probabilistic compromise between the elected candidates, where the likelihood that the policy represented by a candidate emerges as the policy outcome is increasing in the candidate's vote share. ${ }^{4}$ The expected share of rents captured by each candidate is also assumed to be proportional to her vote share in the election.

The main result of the article is that proportional elections have more candidates, competing less aggressively in campaign spending, than those in majoritarian elections. In fact, we show that all candidates in proportional elections (PE) spend less resources campaigning than any majoritarian election (ME) candidate and that under mild conditions, the ranking is strict. Furthermore, in all equilibria in which candidates are ideologically differentiated, the number of candidates

\footnotetext{
${ }^{3}$ As Cox argues, "much of the variance in two of the major variables that electoral systems are thought to influence - namely, the level of disproportionality between each party's vote and seat shares, and the frequency with which a single party is able to win a majority of seats in the national legislature - is explained by this distinction" $(1997,58)$. See the discussion in Lizzeri and Persico (2001).

${ }^{4}$ In this we follow Grossman and Helpman (1996) and Persico and Sahuguet (2006). In the online appendix, we show that our main results do not hinge on the assumption of a probabilistic compromise.
}

running for office is larger in proportional elections (strictly larger under mild conditions) than in majoritarian elections, where exactly two candidates run. We also show that the ideological differentiation between candidates running for office can in general be larger or smaller in proportional than in majoritarian elections.

The results are driven by how platform diversity affects the incentives for entry and the intensity of campaign competition in different electoral systems. In PE, the number of candidates running for office and the degree of ideological differentiation among candidates are determined in equilibrium by two opposing forces. First, candidates must be sufficiently differentiated in the ideological spectrum. This is due to the basic tension between campaign competition and policy differentiation: the closer candidates are in terms of their ideological position, the larger is the number of voters that can be attracted with a given increase in campaigning by one of the candidates. Second, the maximum degree of ideological differentiation among candidates is bounded by entry: candidates cannot be too differentiated in PE without triggering the entry of an additional candidate, who would be able to attain the support of a sufficiently large niche of voters. In contrast to $\mathrm{PE}$, in equilibrium the winner-takes-all feature of majoritarian elections breaks these two links and decouples ideological differentiation, number of candidates, and the intensity of campaign competition.

In the fourth section, we introduce a modified version of PE elections, in which the candidate with a plurality of votes obtains a premium in both the likelihood with which her policy is implemented and in the proportion of office rents she attains after the election (PE-Plus). We show that for a given plurality premium, but sufficiently large electorates, equilibrium behavior in PE-Plus resembles that in ME. This suggests that it is the discontinuity in payoffs implicit in both ME and PE-Plus which induces a decoupling of the intensity of campaign competition from the number of candidates and their ideological differentiation. For a fixed size of the electorate, however, the size of this discontinuity is also relevant. In fact, if the plurality premium is sufficiently small (approximating PE), PE-Plus elections admit equilibria with more than two candidates not fully investing in persuasive campaigning, as in the case of pure PE.

We later consider a variant of the main model in which candidates are perceived by voters as heterogeneous in nonideological attributes even in the absence of any investments in persuasive campaigning. We show that if these attributes cannot be affected during the campaign, then for some parameters it is possible to 
find equilibria in which the nonideological appeal of candidates is larger in PE than in ME. However, if candidates can complement their innate attributes by campaigning, then the nonideological appeal of candidates (inherited and/or acquired) will be higher in ME than in PE, as in the case of the benchmark model.

In an online appendix we show that our main results are qualitatively unchanged if we allow candidates to be both policy and office motivated, as long as the office motivation is sufficiently important. In essence, we can think of the benchmark model as a simplified version of a more general model, where office motivation dominates but does not preclude, policy motivation. In the online appendix we also consider alternative specifications of the policy function mapping elected representatives to policy outcomes. We argue that while the probabilistic compromise that we adopt in the benchmark model simplifies considerably the analysis of electoral equilibria in $\mathrm{PE}$ - by producing vote share functions that are uniquely determined and well-behaved on and off the equilibrium path-it does not bias the results towards lower levels of campaign spending. We show, in particular, that if the policy outcome is selected as the median policy of all elected representatives in the ideological space, PE also admit electoral equilibria with more than two candidates running for office in which no candidate fully invests in persuasive campaigning.

The rest of the article is organized as follows. We review the related literature in the next section. We then introduce the model, present the result and conclude. All proofs are in the online appendix.

\section{Related Literature}

Our article is related to three strands of literature. A first stand focuses on the effect of different electoral systems on the number of candidates running for office. This literature provides several formalizations of the well-known Duvergerian predictions, namely that majoritarian elections leads to a two-party system (Duverger's law) and that PE tends to favor a larger number of parties than ME (Duverger's hypothesis). A relatively large literature focuses on Duverger's law, studying the equilibrium number of candidates in $\mathrm{ME}$ elections. ${ }^{5}$ Among these, the closest to our work are

\footnotetext{
${ }^{5}$ For papers that study entry in ME under the assumption of sincere voting see, e.g., Palfrey (1984) and Greenberg and Shepsle (1987). For papers that study entry in ME under strategic voting, see, e.g., Palfrey (1989), Besley and Coate (1997), and Patty, Snyder, and Ting (2009).
}

Feddersen (1992) and Feddersen, Sened, and Wright (1990) (FSW). Our model of ME differs from these articles on two accounts. First, while in our set-up candidates are endowed with an ideological position that they can credibly implement if elected, in FSW candidates can adjust their ideological positions after entry without costly consequences. Second, while in FSW candidates can only differ in an ideological dimension, in our model candidates can also differentiate themselves by investing in persuasive campaigning. Finally, two articles compare the effect of alternative electoral systems on the number of candidates competing for office. Osborne and Slivinski (1996) compare plurality and plurality with runoff under sincere voting, and Morelli (2004) compares majoritarian and proportional electoral systems under strategic voting. Differently than in our article, Morelli focuses on how different electoral systems influence the incentives of politicians to coordinate their candidacies, addressing more directly the issue of party formation. See also Cox (1997) for an empirical discussion of the Duvergerian predictions.

A second strand analyzes how variations in the electoral system affect policy outcomes. Myerson (1993a) focuses on how the nature of electoral competition affects promises of redistribution made by candidates in the election. Building on this work, Lizzeri and Persico (2001) consider redistribution and provision of public goods in proportional and majoritarian electoral systems. In both articles, the emphasis is not on differentiation (in ideological or nonideological dimensions) but rather on the vote-buying strategies of the candidates. Austen-Smith and Banks (1988), Baron and Diermeier (2001) and Schofield and Sened (2006) consider models of elections and legislative outcomes, where rational voters anticipate the effect of their vote on the bargaining game between parties in the elected legislature. In these articles, however, the number of parties is exogenously given. Finally, several recent articles consider the effects of alternative electoral systems and strategic voting when the relevant policy outcome is not bargaining over a fixed prize, but instead taxation and redistribution (e.g., Austen-Smith 2000; Persson, Roland, and Tabellini 2003), or corruption (e.g., Myerson 1993b; Persson, Tabellini, and Trebbi 2006).

In particular, Myerson (1993b) considers a model where potential candidates are known to differ in their level of corruption (which all voters dislike) but also in a second policy dimension, over which there is disagreement among voters. Myerson concludes that a proportional electoral system is more effective in reducing the probability of selecting a corrupt candidate 
than a majoritarian system. It is interesting to note that-interpreting the persuasive campaigning as investments that reduce the probability of corruption in government-our model yields the opposite result. The reason is that in Myerson (1993b), the level of corruption is an exogenous characteristic of electoral candidates. Together with strategic voting, this assumption is enough to guarantee the existence of an equilibrium in a majoritarian system where exactly two corrupt candidates tie, even if noncorrupt alternatives are available to voters. This cannot occur in a proportional system, where voting sincerely for noncorrupt candidates is a dominant strategy. In our model, candidates' level of corruption in office is endogenous. As a result, the winner-takes-all nature of ME provides the strongest incentive to invest in actions that discourage corruption in office as compared to PE.

Our article is also related to the large literature that, following Stokes (1963)'s original critique to the Downsian model, incorporates competition in valence issues, typically within $\mathrm{ME}$, and with a given number of candidates (two). For recent articles, see Ashworth and Bueno de Mesquita (2009), Carrillo and Castanheira (2008), Eyster and Kittsteiner (2007), Herrera, Levine, and Martinelli (2008), and Meirowitz (2008). ${ }^{6}$ Of these, the closest to ours is Ashworth and Bueno de Mesquita (2009). They show that in a probabilistic voting model with two candidates, candidates have an incentive to "diverge" in the policy space in order to soften valence competition. ${ }^{7}$ While this force is also present in our model for PE, it is not present in majoritarian elections. This is partly due to the assumption that the distribution of voters is known. Indeed, introducing probabilistic voting as in Ashworth and Bueno de Mesquita (2009) or Eyster and Kittsteiner (2007) would smooth the response of the probability of winning the election to changes in campaign spending and thus soften the incentives in campaign competition, making the problem de facto closer to PE.

\section{The Model}

There are three stages in the game. In the first stage, a finite set of potential candidates simultaneously decide whether or not to run for office. In the second stage, all candidates running for office simultaneously

\footnotetext{
${ }^{6}$ See also Groseclose (2001), Aragones and Palfrey (2002), Schofield (2004), and Kartik and McAfee (2007) for models where one candidate has an exogenous valence advantage.

${ }^{7}$ A similar result is found by Eyster and Kittsteiner (2007), where parties compete in elections for heterogenous constituencies, and there is uncertainty over the distribution of voters' ideal policies.
}

choose a level of campaign investment. In the third stage, a finite set of strategic voters vote.

For given $T$, define the ideology space $X \equiv\left\{t / 2^{T}: t=0,1, \ldots, 2^{T}\right\} \subset[0,1]$, where we think of $T$ as being a large number. ${ }^{8}$ In any $x \in X$ there are at least two potential candidates, each of whom will perfectly represent ideology $x$ if elected. In the first stage, all potential candidates simultaneously decide whether or not to run for office. Potential candidates only care about the spoils they can appropriate from being in office and must pay a fixed cost $F$ to participate in the election. ${ }^{9}$ We denote the set of candidates running for office at the end of the first stage by $\mathcal{K}=\{1, \ldots, K\}$. In the second stage, all candidates running for office simultaneously choose a level of campaign investment $\theta_{k} \in[0,1]$. Candidates can invest $\theta_{k}$ at a cost $C\left(\theta_{k}\right)$, where $C(\cdot)$ is an increasing and convex function. We let $C(1) \equiv \bar{c}$ and-to allow competitive elections in all electoral systemswe assume that $F+\bar{c} \leq 1 / 2$. In the third stage, $n$ fully strategic voters vote in an election, where $n$ is a (large) finite number. A voter $i$ with ideal point $z^{i} \in X$ ranks candidates according to the utility function $u\left(\cdot ; z^{i}\right)$, which assigns to candidate $k$ with characteristics $\left(\theta_{k}, x_{k}\right)$ the payoff $u\left(\theta_{k}, x_{k} ; z^{i}\right) \equiv 2 \alpha v\left(\theta_{k}\right)-\left(x_{k}-z^{i}\right)^{2}$, with $v$ increasing and concave. The parameter $\alpha$ captures voters' responsiveness to persuasive campaigning. Voters' ideal points are uniformly distributed in $X$. Finally, for any $\theta \in[0,1]$, let $\Psi(\theta) \equiv v^{\prime}(\theta) / C^{\prime}(\theta)$.

The electoral system determines the mapping from voting profiles to policy outcomes and the allocation of rents. In majoritarian elections (ME), the candidate with a plurality of votes appropriates all rents from office and implements the policy she represents. In proportional elections (PE), each candidate $k \in K$ obtains a share of the total seats in the legislature equal to her share of votes in the election, $s_{k}$. The policy outcome is the result of a probabilistic compromise between the elected candidates, where the likelihood of the policy represented by a candidate emerging as the policy outcome is increasing in the candidate's vote share or seat share in the assembly (see Grossman and Helpman 1996 and Persico and Sahuguet 2006 for a similar assumption). The (expected) share of rents captured by candidate $k$, denoted $m_{k}$, is

\footnotetext{
${ }^{8}$ In all our formal analysis of proportional elections (PE), we consider the limit of the discrete case as $T \rightarrow \infty$ and treat both the policy space and the set of potential candidates as an interval of $\mathbb{R}$. As it will become clear in the analysis, this simplification does not sacrifice anything of importance.

${ }^{9}$ In the online appendix, we show that results are robust to introducing policy motivation to run for office.
} 
proportional to her vote share in the election, $s_{k}$. Let $\theta_{\mathcal{K}} \equiv\left\{\theta_{k}\right\}_{k \in \mathcal{K}}$, and $x_{\mathcal{K}} \equiv\left\{x_{k}\right\}_{k \in \mathcal{K}}$ denote the level of persuasive campaigning and policy positions of the candidates running for office. Normalizing total political rents in both systems to one, the expected payoff of a candidate $k$ running for office in electoral system $j$ can then be written as

$$
\begin{aligned}
\Pi_{k}^{j}\left(\mathcal{K}, x_{\mathcal{K}}, \theta_{\mathcal{K}}\right)= & m_{k}^{j}\left(\theta_{\mathcal{K}}, x_{\mathcal{K}}\right)-C\left(\theta_{k}\right) \\
& -F \text { for } j \in\{M E, P E\} .
\end{aligned}
$$

For simplicity, and without any real loss of generality, we assume that $m_{k}^{P E}\left(\theta_{\mathcal{K}}, x_{\mathcal{K}}\right)=s_{k}\left(\theta_{\mathcal{K}}, x_{\mathcal{K}}\right)$. We also assume that in ME ties are broken by the toss of a fair coin, so that letting $H_{k} \equiv\left\{h \in \mathcal{K}: s_{k}=s_{h}\right\}$,

$$
m_{k}^{M E}\left(\theta_{\mathcal{K}}, x_{\mathcal{K}}\right)=\left\{\begin{array}{rr}
\frac{1}{\left|H_{k}\right|} & \text { if } s_{k} \geq \max _{j \neq k}\left\{s_{j}\right\} \\
0 & \text { o.w. }
\end{array}\right.
$$

A strategy for candidate $k$ is a decision of whether to run for office or not $e_{k} \in\{0,1\}$ and a campaign investment $\theta_{k}\left(\mathcal{K}, x_{\mathcal{K}}\right) \in[0,1]$. A strategy for voter $i$ is a function $\sigma_{i}\left(\mathcal{K}, x_{\mathcal{K}}, \theta_{\mathcal{K}}\right) \in \mathcal{K}$, where $\sigma_{i}\left(\mathcal{K}, x_{\mathcal{K}}, \theta_{\mathcal{K}}\right)=k$ indicates the choice of voting for candidate $k$, and $\sigma=\left\{\sigma_{1}(\cdot), \ldots, \sigma_{N}(\cdot)\right\}$ denotes a voting strategy profile. An electoral equilibrium is a Subgame Perfect Nash Equilibrium in pure strategies of the game of electoral competition in which voters do not use weakly dominated strategies, i.e., a strategy profile such that (1) voters cannot obtain a better policy outcome by voting for a different candidate in any voting game (on and off the equilibrium path), (2) given the location and campaign decisions of other candidates, and given voters' voting strategy, candidates cannot increase their expected rents by modifying their campaign levels, (3) candidates running for office obtain non-negative rents, and (4) candidates not running for office prefer not to enter: they would obtain negative rents in an equilibrium of the continuation game. Ruling out weakly dominated strategies restricts the behavior of nonpivotal voters, requiring that they do not vote for their least preferred alternative. An outcome of the game is a set of candidates running for office $\mathcal{K}$, policy positions $x_{\mathcal{K}}$, and campaign investments $\theta_{\mathcal{K}}$. A polity is a quadruple $(\alpha, \bar{c}, F, \Psi(1)) \in \Re_{+}^{4}$. We say that the model admits an electoral equilibrium with outcome $\left(\mathcal{K}, x_{\mathcal{K}}, \theta_{\mathcal{K}}\right)$ if there exists a set of polities $P \subseteq \Re_{+}^{4}$ with positive measure such that whenever $p \in P$, there is an electoral equilibrium with outcome $\left(\mathcal{K}, x_{\mathcal{K}}, \theta_{\mathcal{K}}\right)$.

Before moving on to describe our main result, it is worth discussing briefly our interpretation of the relationship between campaign spending and electoral outcomes. Candidates invest in persuasive campaigning for a good reason: it works (see Coleman and Manna 2000; Erikson and Palfrey 2000; and Green and Krasno 1988). In most of this articles we take this relationship as is, black-boxing the underlying mechanism by which voters' choices are affected by campaigning. There are, however, a number of channels through which campaign activities can affect voters' willingness to vote for a candidate.

First, running an effective modern political campaign demands a substantial organization "on the ground." Developing these networks and infrastructure requires devoting significant time, effort, and resources. Schofield and Sened (2006) explores the role of political activists in elections. Second, by selecting high-quality staff, researching appropriate responses to current events, and shaping drafts of future policies, candidates are-and are seen by voters as being-more likely to succeed in office. Third, persuasive campaign can be effective in reducing uncertainty about the policy that the candidate will implement once in office. This idea was first formalized by Austen-Smith (1987) and received empirical support in Coleman and Manna, who show that "Campaign spending increases knowledge of and affect toward the candidates, improves the public's ability to place candidates on ideology and issue scales, and encourages certainty about those placements" $(200,757)$.

Our model is fully consistent with this mechanism after a simple reformulation. In this reformulation, we interpret the common value dimension in the model as reflecting the electorate's uncertainty about the true positions that candidates will champion once in office. In particular, when the policy payoff function is quadratic as in our model, we can recover the exact benchmark model starting from primitives. Suppose then that $U\left(x_{k}, z^{i}\right)=-\beta\left(x_{k}-z^{i}\right)^{2}$ and that the policy $y_{k}$ of candidate $k$ is perceived by voters to be distributed uniformly on $\left[x_{k}-\epsilon(\theta), x_{k}+\epsilon(\theta)\right]$, where $\epsilon(\cdot)$ is a decreasing and convex function of the investment in persuasive campaign $\theta$. Then the expected utility of a voter with ideal point $z^{i}$ can be written as $E\left[U\left(y_{k}, z^{i}\right) ; \theta\right]=-\beta\left(x_{k}-z^{i}\right)^{2}+v(\theta)$, where $v(\theta)$ is an increasing and concave function of $\theta$.

\section{Results}

We begin our analysis by considering proportional electoral systems. Proposition 1 establishes the core result for proportional elections (PE). First, we provide sufficient conditions for the existence of an 
electoral equilibrium in $\mathrm{PE}$ in which more than two candidates run for office without fully investing in persuasive campaigning. Furthermore, we show that $\mathrm{PE}$ do not generically admit electoral equilibria in which different candidates represent the same policy.

Proposition 1. If $K \cdot \min \{2 \bar{c}, \alpha \Psi(1)\}<1$, proportional elections (1) admit electoral equilibria in which $K \geq 3$ candidates run for office without fully investing in persuasive campaigning, and (2) do not admit electoral equilibria in which only two or more centrist candidates run for office and no other candidates run.

To prove this result we provide conditions for the existence of electoral equilibria of a simple class, which we call location symmetric (LS) equilibria. In equilibria of this class, all candidates running for office are located at the same distance to their closest neighbors in the ideological space; i.e., $x_{k+1}-x_{k}=\Delta$ for all $k=1, \ldots, K-1, x_{1}=1-x_{K}=\Delta_{0}$, and all interior candidates $k=2, \ldots, K-1$ choose the same level of investment in persuasive campaigning. The number of candidates running for office and the degree of ideological differentiation between candidates are determined in equilibrium by two opposing forces. First, in any electoral equilibrium in PE, candidates must be sufficiently differentiated in the ideological spectrum, because of the basic tension that emerges between persuasive campaigning and differentiation in policies: the closer candidates are in terms of their ideological position, the larger is the effect of persuasive campaigning by any of the candidates. This is the first channel linking strategic entry decisions, ideological differentiation, and persuasive campaigning in PE. To see how this channel operates in our LS equilibrium, consider two candidates $k$ and $k^{\prime}>k$ with policy positions $x_{k}$ and $x_{k^{\prime}}>x_{k}$ and choosing persuasive campaign investment levels $\theta_{k}$ and $\theta_{k^{\prime}}$, and let $\tilde{x}_{k, k^{\prime}} \in \mathcal{R}$ denote the (unique) value of $x$ for which $u\left(\theta_{k}, x_{k} ; x\right)=u\left(\theta_{k^{\prime}}, x_{k^{\prime}} ; x\right)$, so that $u\left(\theta_{k}, x_{k} ; z^{i}\right)>u\left(\theta_{j}, x_{j} ; z^{i}\right)$ if and only if $z^{i}>\tilde{x}_{k, j}$,

$$
\tilde{x}_{k, k^{\prime}}=\frac{x_{k}+x_{k^{\prime}}}{2}+\alpha \frac{\left[v\left(\theta_{k}\right)-v\left(\theta_{k^{\prime}}\right)\right]}{\left|x_{j}-x_{k}\right|} .
$$

In a LS equilibrium, $k$ 's only relevant competitors are neighbors $k-1$ and $k+1 .{ }^{10}$ Because of probabilistic compromise, policy is equal to the platform of

\footnotetext{
${ }^{10}$ This is enough to show that payoff functions are twice differentiable in the relevant set (nondifferentiabilities can only arise for campaigning choices that are not optimal) and that whenever rents cover variable costs, first-order conditions in the investment subgame completely characterize best-response correspondences. See Iaryczower and Mattozzi (2012) for more details.
}

candidate $k$ with probability proportional to $k$ 's share of votes in the election. As a result, in equilibrium voters vote for their preferred candidate. (When voter $i$ votes for candidate $k$, she affects the probability distribution over outcomes by increasing the weight of candidate $k$ 's position. But then voting for a candidate other than the most preferred one is always a strictly dominated strategy. $)^{11}$ Thus $k$ 's vote share is $s_{k}\left(\theta_{k} ; \theta_{-k}, x\right)=\tilde{x}_{k, k+1}-\tilde{x}_{k-1, k}=\Delta$, and therefore from (1) for PE, the payoff for an interior candidate $k=2, \ldots, K-1$ is

$$
\begin{aligned}
& \Pi_{k}\left(\theta_{\mathcal{K}}, x_{\mathcal{K}}, \mathcal{K}\right)= \\
& \quad \Delta+\alpha\left[\frac{v\left(\theta_{k}\right)-v\left(\theta_{k+1}\right)}{\Delta}+\frac{v\left(\theta_{k}\right)-v\left(\theta_{k-1}\right)}{\Delta}\right] \\
& \quad-C\left(\theta_{k}\right)-F .
\end{aligned}
$$

Defining $\Psi(\theta) \equiv v^{\prime}\left(\theta_{k}\right) / C^{\prime}\left(\theta_{k}\right), k^{\prime}$ s best response is then

$$
\theta_{k}^{*}=\left\{\begin{array}{cc}
\Psi^{-1}\left(\frac{\Delta}{2 \alpha}\right) & \text { if } \Psi^{-1}\left(\frac{\Delta}{2 \alpha}\right) \leq 1 \\
1 & \text { if } \Psi^{-1}\left(\frac{\Delta}{2 \alpha}\right)>1 .
\end{array}\right.
$$

Similarly, for an extreme candidate, say $k=1$, its best response is $\theta_{1}^{*}=\Psi^{-1}(\Delta / \alpha)$ as long as $\Psi^{-1}(\Delta / \alpha) \leq 1$, and $\theta_{1}^{*}=1$ otherwise.

Noting that $\Psi(\cdot)$ is a decreasing function, it follows that candidates will be more aggressive in campaigning the closer they are to one another, eventually competing away their rents. Candidates that are sufficiently differentiated in the ideological dimension, instead, are not close substitutes for voters. In this case, PE leads to low-powered incentives, nonideological competition is relaxed, and candidates running for office can choose lower (less costly) levels of persuasive campaigning while still getting a positive share of office rents in equilibrium. To sum up, the strategic effect of ideological differentiation (on the aggressiveness in campaigning) imposes a lower bound on differentiation in equilibrium.

The second channel linking strategic entry decisions, ideological differentiation, and persuasive campaigning in PE derives from the fact that the limit to the degree of horizontal differentiation among candidates is given by the threat of entry: candidates cannot be too differentiated in PE without triggering entry of an additional candidate, who would be able-given sincere voting in

\footnotetext{
${ }^{11}$ A detailed proof can be found in the online appendix (Lemma 1). The fact that strategic voting boils down in PE to sincere voting greatly simplifies the characterization of electoral equilibria, assuring uniquely determined, smooth, and well-behaved vote share functions for all candidates on and off the equilibrium path.
} 
the electorate-to attain the support of a sufficiently large niche of voters. The same logic implies in fact that $\mathrm{PE}$ do not admit an electoral equilibrium in which two or more perfectly centrist candidates run for office. If all candidates running for office were centrist, it would always be possible for a candidate representing a policy position close to the median to run for office, capturing almost half of the votes. Since the centrist candidates were making nonnegative rents in the proposed equilibrium, the entrant's expected payoff from running must be positive as well, and there is no way to deter his entry. As a result, the fully centrist equilibrium in ME cannot be generically supported in PE.

In the proof we show how to obtain an upper bound on differentiation among equilibrium candidates as a sufficient condition to guarantee that for any possible nonequilibrium entrant, there exists an equilibrium of the continuation game in which the entrant would make negative rents. We then show that there exists a nontrivial set of parameters for which all the previous conditions on $\Delta$ are simultaneously satisfied. In particular, we show that for a LS equilibrium with $K \leq 3$ candidates not fully investing in persuasive campaigning to exist, it is sufficient that (1) the responsiveness of voters to campaigning is not too high (i.e., $\alpha<\bar{\alpha}(K) \equiv \Psi^{\prime}(1) /(2 K)$ ), that (2) the fixed cost of running for office is always larger than the cost of campaigning (i.e., $F>\bar{c}$ ), and that (3) the fixed cost of running for office is not too low (to deter entry) or too high (for nonnegative rents); i.e., $1 / 2 K<F<1 / K-\bar{c}$. Note in particular that we can support equilibria with an increasingly larger number of candidates given sufficiently lower costs of running for office and of campaigning and a sufficiently smaller responsiveness of voters to persuasive campaign - equivalently, a sufficiently larger ideological focus of voters (Stokes 1963).

In contrast to $\mathrm{PE}$, in equilibrium the winner-takes-all feature of majoritarian elections breaks the links between platform diversity, entry, and the intensity of campaign competition. First, we show that Duverger's law holds in almost all electoral equilibria. Although many candidates can run for office, majoritarian elections trim down competition between differentiated candidates to two candidates, each of whom invest as much as possible in persuasive campaigning. The degree of ideological differentiation between candidates, however, is not pinned down by equilibrium: majoritarian elections admit both an equilibrium with two centrist candidates and one in which candidates are maximally polarized (as well as any symmetric configuration). For some parameter values, there also exists an equilibrium in which more than two perfectly centrist (and in all respects identical) candidates run for office. We summarize these results in Proposition 2.

Proposition 2. In a majoritarian election an electoral equilibrium always exists. In any equilibrium in which candidates represent different ideological positions: (1) exactly two candidates compete for office, (2) candidates are symmetrically located around the median in the policy space, and (3) both candidates fully invest in persuasive campaigning (i.e., $\theta_{1}^{*}=\theta_{2}^{*}=1$ ).

To see the intuition for the result, note first that given the winner-takes-all nature of majoritarian elections, all candidates running for office must tie in equilibrium. From this it follows that (a) voters must vote sincerely and that $(b)$ candidates must fully invest in persuasive campaigning. To see that there cannot be an electoral equilibrium with $K>2$ differentiated candidates running for office, note that if this were the case, $(a)$ and $(b)$ imply that by deviating and voting for any candidate $j$ other than her preferred candidate, a voter could get candidate jelected with probability one. Revealed preference from equilibrium therefore implies that this voter must prefer the lottery among all $\mathcal{K}^{\star}$ candidates running for office to having $j$ elected for sure. Furthermore, strict concavity of voters' preferences imply that any voter must strictly prefer the "expected candidate" (to the equilibrium lottery, and therefore) to having candidate $j$ elected for sure. But this leads to a contradiction, since when $K>2$, a voter that is almost indifferent between her first and second most preferred candidate always prefers the ideological position of her second most preferred candidate to that of the expected candidate. Since in any equilibrium there cannot be more than two candidates representing different ideological positions, they must be symmetrically located with respect to the median of the ideological space.

Therefore, in equilibrium, we must have exactly two symmetrically located candidates fully investing in persuasive campaigning. ${ }^{12}$ In the proof we show that such an equilibrium exists, and that there is, in fact, a multiplicity of two-candidate symmetric equilibria, with candidates fully investing in persuasive campaigning.

Propositions 1 and 2 show that proportional elections have more candidates, competing less aggressively in campaign spending, than those in majoritarian elections. This is our main result.

\footnotetext{
${ }^{12}$ Feddersen, Sened, and Wright (1990) use a similar argument in a pure private values model in which candidates decide both whether to enter or not and which policy position they will represent.
} 
Theorem 1 (1) In any admissible electoral equilibrium in PE, (a) all candidates running for office spend (weakly) less in campaigning than any candidate does in any admissible equilibrium in $M E$, and (b) the number of candidates running for office is (weakly) larger than the number of candidates in any admissible equilibrium in $M E$ in which candidates are differentiated. Moreover, (2) PE admit electoral equilibria for which the above comparisons are strict.

It is important to emphasize that the assumption that total office rents are equal in both systems (which we have maintained so far for simplicity of presentation) is irrelevant for Theorem 1 . The result is not due to what we can call an "accounting" effectwhereby candidates compete less aggressively in PE because they anticipate a smaller share of the pie-but instead to incentives and equilibrium behavior. In fact, we can obtain the same ranking across systems even if the rents per candidate running in the election are higher in PE. ${ }^{13}$

It is also worth noting that Theorem 1 holds unchanged in a multidimensional policy space. As it is clear from the proof of Proposition 1, the logic for LS equilibria in $\mathrm{PE}$ elections is fundamentally unchanged in multiple dimensions. Because of sincere voting, the vote shares are smooth and monotonic to campaign effort, as in a single-dimensional policy space. The most relevant difference between $\mathbb{R}^{1}$ and say $\mathbb{R}^{2}$, is that instead of at most two relevant competitors, each party now faces at most four relevant competitors, and therefore there is a higher marginal effect of investing resources in persuasive campaigning. This complicates the algebra, but only changes the parametric conditions under which there exist a LS equilibrium with $K$ parties not attaining the campaign limits. Now consider ME elections. As in one dimension, on the equilibrium path candidates must anticipate to tie and must fully invest in persuasive campaigning, and voters must vote sincerely. What must be shown is that also in this case only two candidates run for office in equilibrium. But this follows from the above properties and concavity of the policy payoffs.

We close this section with a remark about welfare: is either a majoritarian or proportional electoral system

\footnotetext{
${ }^{13}$ Let $B^{M E}$ and $B^{P E}$ denote the total rents in $\mathrm{ME}$ and $\mathrm{PE}$ respectively. Then we can write $j$ 's objective function as $\Pi_{k}^{j}\left(\mathcal{K}, x_{\mathcal{K}}, \theta_{\mathcal{K}}\right)=m_{k}^{j}\left(\theta_{\mathcal{K}}, x_{\mathcal{K}}\right)-C\left(\theta_{k}\right) / B^{j}-F / B^{j}$. Proposition 2 shows that there exists an equilibrium with two parties and maximum campaigning in $\mathrm{ME}$ as long as $F+\bar{c} \leq B^{M E}$, which we are assuming throughout. From Proposition 1, as long as $B^{M E} \leq 4 F$ and $B^{M E}<2 / 9 \alpha \Psi(1)$, it is possible for rents per capita in $\mathrm{PE}$ to be larger than in ME and still have an equilibrium in $\mathrm{PE}$ with three parties not attaining campaign limits.
}

generically better for voters? The answer is no, or more precisely, not without making further assumptions and imposing a particular criterion for selecting among equilibria. As we pointed above, all of our results so far hold without assuming (strict) concavity of the voters' policy payoff function (which is implicit in our quadratic representation of policy preferences). Without assuming concavity, however, not much can be said about the efficiency of alternative electoral systems within this framework. If one is willing to maintain that the assumption of concavity of voters' payoff function holds generically, then some limited welfare results follow.

First, for any given parameter values, the best equilibrium in ME is better for voters than the best equilibrium in PE. Within the class of LS equilibria under $\mathrm{PE}$, the welfare comparison comes as an immediate corollary of our previous results, for we know that it is not possible to have convergence in PE elections. Given the same level of investment in persuasive campaigning, concavity of voters' preferences implies that any voter strictly prefers the expected candidate with ideological position corresponding to the expected value of the equilibrium lottery to the lottery itself. The same result holds more generally for any electoral equilibrium in PE: for any equilibrium in PE, any voter prefers the expected candidate of the equilibrium lottery to the lottery itself. If this expected candidate is centrist, then as before, we are done. If not, then still the concavity of voters' preferences implies that a centrist candidate will be preferred by a majority of voters to the expected candidate.

Second, the ranking of the worst equilibria for voters does depend on parameter values. The worst equilibrium in ME given any feasible parameter configuration has two extreme candidates exhausting all resources available for persuasive campaigning. On the other hand, the worst equilibrium that can be supported in PE for some parameter configuration has two extreme candidates slacking in persuasive campaigning effort. For other feasible parameter configurations, however, the worst equilibrium for voters in $\mathrm{PE}$ has $K \geq 3$ candidates exhausting all resources available for persuasive campaigning. All in all, the results in terms of welfare comparison are ambiguous.

\section{A Plurality Premium in PE}

In our stylized model of proportional elections, each candidate running for office captures a proportion of office rents equal to her share of votes in the election. In various political systems, however, the party with a plurality of votes obtains an additional reward over 
and above its share of votes in the election. In several parliamentary democracies, for instance, the formateur is typically the head of the majority party.

To gain insight about this problem, we consider an abstract electoral system that incorporates the key feature of ME into our model of PE elections. In this modified version of the model-which we call PE-plus - the candidate with a plurality of votes obtains a premium $\gamma \in(0,1)$ in both the likelihood with which her policy is implemented and in the proportion of office rents she attains after the election. PE-plus can then be thought of as an intermediate electoral system between $\operatorname{PE}(\gamma=0)$, and $\operatorname{ME}(\gamma=1)$. Letting as before $H_{k} \equiv\left\{h \in \mathcal{K}: s_{k}=s_{h}\right\}$, k's proportion of office's rents after the election is given by

$$
m_{k}=\left\{\begin{array}{cc}
s_{k}(1-\gamma)+\frac{\gamma}{\left|H_{k}\right|} & \text { if } s_{k} \geq \max _{j \neq k}\left\{s_{j}\right\} \\
s_{k}(1-\gamma) & \text { o.w. }
\end{array}\right.
$$

The next result characterizes PE-plus elections in large finite electorates. We show that in large electorates there exists an electoral equilibrium with two candidates symmetrically located around the median voter fully investing in persuasive campaigning, provided that the candidates are not too polarized. We also show that for any plurality premium $\gamma$, electoral equilibria in large elections are either of this kind or such that a single candidate appropriates the plurality premium with certainty.

\section{Proposition 3.}

(1) There exists $\bar{n}$ such that for all $n \geq \bar{n}$, there is an electoral equilibrium in which two candidates symmetrically located around the median voter run for office fully investing in persuasive

(2) Fix any sequence of equilibria $\left\{\tilde{\Gamma}_{n}\right\}_{n_{0}}^{\infty}$. There exists $\bar{n}$ such that if $n \geq \bar{n}$, then in $\tilde{\Gamma}_{n}$, either two symmetrically located candidates run for office fully investing in persuasive campaigning, or a single candidate appropriates the plurality premium with certainty.

The proof of this proposition can be found in the online appendix. The main intuition for existence of equilibria with two candidates fully investing in persuasive campaigning is that for any plurality premium $\gamma$, and sufficiently large electorates, the strategic problem of individual voters in PE-plus resembles the analogous problem in ME. As a result, we can support an equilibrium with two candidates, 1 and 2, by having voters coordinate on voting for their preferred choice among these candidates, even after entry of a third candidate $l$. To see this, consider without loss of generality a voter $i$ with preferences $l>_{i} 1>_{i} 2$ (note that we only need strategic voting among voters whose preferred candidate in $\{1,2, l\}$ is the entrant, $l$ ). Voter $i$ faces the following trade-off. On the one hand, by switching to vote sincerely in favor of the entrant, the voter is transferring $1 / n$ probability mass from his second best candidate $(k=1)$ to his most preferred candidate $(l)$. On the other hand, he is also inducing a jump of $\gamma / 2$ in the probability that the policy of his least favorite candidate in $\{1,2, l\}$ emerges as the policy outcome, to be "financed" by a similar decrease in the probability of his second best candidate's policy being chosen. For large $n$, the second effect dominates, and $i$ has incentives to vote strategically. The intuition for the second part of the proposition follows along the same lines and is only slightly more involved.

The previous result should not be interpreted as implying a complete discontinuity with the PE environment. Note that for fixed $n$, and given a strategy profile for all other voters, the incentive to vote strategically increases monotonically in the plurality premium $\gamma$, and in the polarization of candidates 1 and 2: for any strategy profile of the remaining voters, if $i$ has an incentive to vote strategically given some $\gamma$, then $i$ also has an incentive to vote strategically given $\gamma^{\prime}>\gamma$. Similarly, if $i$ has an incentive to vote strategically for some given degree of ideological differentiation between candidates 1 and 2, then $i$ also has an incentive to vote strategically for a larger payoff differential among equilibrium candidates. In fact, it is easy to see that if candidates running for office are not at all differentiated, then there cannot be strategic voting of this type, as in this case supporting the preferred candidate comes at not cost. But this implies that there cannot be electoral equilibria with perfect convergence in PE-plus. On the other hand, in general candidates cannot be too polarized either, for otherwise a deviation by one of the candidates to less effort in persuasive campaigning, forgoing the plurality premium, can be profitable for sufficiently small $\gamma$. All in all, while equilibrium behavior of voters and candidates in PE-plus can resemble behavior in ME, the set of equilibria of this class has to be pruned to rule out complete convergence and under some conditions also extreme polarization.

A natural question at this point is whether equilibria with three or more candidates running for office without fully investing in persuasive campaigningwhich we have shown can be supported in equilibrium in PE—can survive in the case of PE-plus. The answer is yes, provided that the size of the plurality premium is not too large. To see this, note first that whenever a 
candidate is ahead by at least two votes in PE-plus, strategic voting must be sincere, since in this case any individual deviation in the voting strategy cannot affect the identity of the majority candidate. With this result in mind, consider a location symmetric equilibrium in PE $(\gamma=0)$ such that three candidates run for office without fully investing in persuasive campaigning, and the centrist candidate obtains the sincere vote of slightly more than a third of the electorate. Consider now the case of a positive but small premium $\gamma$. From our previous remark, sincere voting remains a best response when other voters vote sincerely. Moreover, with small enough $\gamma$, winning a plurality of the vote is not worth a deviation from the optimal campaign investment in the pure PE environment. Finally, note that if the entry of a fourth candidate was not profitable in the case of $\gamma=0$, this has to be true also in the case of a small plurality premium. In fact, it is enough for this that when $\gamma=0$, the equilibrium candidates' rents in the continuation game following entry are strictly positive, but we know that this will be the case generically.

To sum up, we have shown that for a given plurality premium, but sufficiently large electorates, equilibrium behavior in PE-Plus resembles that in ME. This suggests that it is the discontinuity in payoffs implicit in both ME and PE-Plus which induces a decoupling of the intensity of campaign competition from the number of candidates and their ideological differentiation. For a fixed size of the electorate, however, the size of this discontinuity is also relevant. In fact, if the plurality premium is sufficiently small (approximating PE), PE-Plus admit equilibria with more than two candidates not fully investing in persuasive campaigning, as in the case of pure PE.

\section{Pre-Campaign Heterogeneity: A Model of Selection}

In the benchmark model we assume that candidates are perceived by voters as homogeneous in nonideological attributes before any effort is devoted to campaigning. In this section we consider a variant of the main model in which candidates are heterogeneous in nonideological attributes even in the absence of any investments in persuasive campaigning. We consider two possible variations of the sequence of the benchmark choice model.

1. In the selection model we assume that candidates are endowed with both an ideological position and a level $\theta_{k}$ of an observable attribute that captures their exogenous appeal to voters. Candidates cannot, however, invest resources to make the alternative they represent more appealing to voters.
2. In the selection + choice model, candidates are heterogeneous with respect to their exogenous appeal to voters as in the selection model but can also invest in persuasive campaign as in our benchmark choice model.

We begin with the analysis of the selection model. We assume that there is a candidate representing each point in the attribute-ideology space and that candidates with higher level of $\theta$ have a higher opportunity cost of running for office $c(\theta)$. To make the results comparable to the benchmark choice model, we represent the opportunity cost of types in the selection model with the same cost function $C(\cdot)$ of the benchmark model, so that $c(\theta) \equiv C(\theta)$. The action space of candidates is therefore restricted to a decision of whether or not to run for office.

To see how the alternative electoral systems operate in the selection model, consider first ME. As in the choice model, the winner-takes-all nature of ME implies that potential candidates will run for office only if they have a strictly positive expected probability of winning. Furthermore, in any equilibrium in which candidates are differentiated, only two candidates will run for office (the argument used in the proof of Proposition 2 builds on deviations by voters for a given set of candidates and can therefore be applied in this case as well). These properties imply that voters must vote sincerely between the two candidates running for office on the equilibrium path and therefore that these candidates must be symmetrically located around the median voter. As a consequence, any configuration of candidates' characteristics that can be supported as an equilibrium of the choice model in ME can also be supported as an equilibrium of the selection model.

Contrary to the choice model, however, every symmetric configuration of candidates (in both location and level of $\theta$ ) can be supported as an equilibrium of the selection model. In fact, in this alternative timing specification-a simultaneous game of entry-strategic voting is effective in deterring entry of any third candidate irrespectively of his characteristics.

Consider now LS equilibria in PE. First, note that voting is still sincere on and off the equilibrium path in all equilibria. Second, note that if there is a candidate running for office with policy position $x_{k}$ and $\theta_{k}<1$, who earns strictly positive rents, the same must be true for an alternative candidate with identical ideological position $x_{k}$ and $\theta_{k}^{\prime}>\theta_{k}$. Therefore in any LS equilibrium of the selection model, candidates either reach the bounds on campaign spending or make zero rents. This implies that if $x_{k}-x_{k-1} \equiv \Delta>\bar{c}+F$ 
in a LS equilibrium of the choice model with $K \geq 3$ (i.e., candidates are sufficiently differentiated so that interior candidates would earn positive rents even choosing $\theta_{k}=1$ ), then in the selection model it must be that $\theta_{k}=1$ for all interior candidates. ${ }^{14}$ If, on the other hand, $K \geq 3$ and $\Delta<\bar{c}+F$ in a LS equilibrium of the choice model (i.e., candidates choosing $\theta_{k}=1$ would earn negative rents), then the equilibrium level of $\theta$ of both the choice and the selection model would be interior. Summarizing, if candidates earn no rents at the equilibrium $\theta^{\star}<1$ in the choice model, then $\theta^{\star}<1$ will also be the equilibrium of the selection model; if instead candidates earn positive rents in the choice model, then the equilibrium of the selection model will be characterized by a higher level of $\theta \cdot{ }^{15}$ We conclude the following.

Remark 1 The selection model allows "mediocre" candidates to run for office in majoritarian elections and leads to higher level of $\theta$ than the choice model in proportional elections. Hence there exists a selection of equilibria such that the nonideological appeal of candidates (inherited) is larger in proportional than in majoritarian elections. The conclusions regarding the number of candidates do not change throughout.

The driving force behind this result is that the selection model introduces more competition among candidates in PE: if a mediocre candidate is not completely dissipating his rents in an equilibrium of the selection model in PE, a candidate with higher $\theta$ would find it profitable to run for office as well. This is not the case in the choice model, where competition in persuasive campaign takes place among a given set of candidates running for office. On the other hand, in the selection model under ME, strategic voting can prevent the entry of any third candidate irrespectively of his characteristics, as in Myerson (1993b).

As we argued in the introduction, however, the assumption that candidates cannot complement their initial appeal (if any) with campaign actions seems unwarranted. Candidates are largely defined for voters during campaigns. Interestingly, when candidates

\footnotetext{
${ }^{14}$ Either (1) in the equilibrium of the choice model candidates choose $\theta^{\star}=1$, in which case the same thing must be true in the selection model or (2) in the choice model candidates choose $\theta^{*}<1$, so that for any position $x_{k}$ rents must be positive for $\theta_{k} \in\left[\theta^{*}, 1\right)$, and thus $\theta_{k}=1$ for all interior candidates in the selection model. If also $\Delta<1 / K$, extreme candidates must choose $\theta^{\star}=1$ too, for $\Delta<1 / K$ implies that extreme candidates obtain higher rents than interior candidates.

${ }^{15}$ The level of $\theta$ in the equilibrium of the selection model will still not be maximal since rents are decreasing in $\theta_{k}$ for $\theta_{k} \in\left[\theta^{\star}, 1\right)$ and negative at $\theta_{k}=1$, so must be zero at some $\bar{\theta}_{k}<1$. In Iaryczower and Mattozzi (2012), we show that PE elections admit equilibria with $K \geq 3$ and $\Delta<\bar{c}+F$.
}

can complement their initial perceived differences through campaign actions, as in the selection + choice model, the tension between the choice and the selection models is resolved in favor of the benchmark choice model: the nonideological appeal of candidates (inherited and/or acquired) is larger in ME than in PE.

Within the selection + choice model, denote by $\theta_{k}^{s}$ the exogenous component of the overall appealing to voter of candidate $k$ 's alternative, and by $\theta_{k}^{c}$ the endogenous component due to persuasive campaign, where $\theta_{k}^{s}+\theta_{k}^{c} \in[0,1]$. Note that in equilibrium $\theta_{k}^{c}$ will be a function of $\theta_{k}^{s}$. As in the selection model, candidates with higher $\theta^{s}$ have a higher opportunity cost of running for office $c\left(\theta^{s}\right)$. As in the choice model, candidates running for office can also add to their exogenous appeal to voters by investing in persuasive campaign at a cost $\hat{c}\left(\theta^{c}\right)$. In order to make the results comparable to the benchmark choice model, we also assume that $c\left(\theta^{s}\right)+\hat{c}\left(\theta^{c}\right) \equiv C\left(\theta^{s}+\theta^{c}\right)$, where $C(\cdot)$ is the same cost function of the benchmark model.

Consider first majoritarian elections. It is immediate to verify that strategy profiles such that $\theta_{k}^{s}+\theta_{k}^{c}<1$ for some $k$ can not be electoral equilibria, for-as in the benchmark choice model-this would give $k$ a profitable deviation. We conclude that the difference between the results of the choice and the selection models entirely relies on the somewhat knife-edge assumption that, during the campaign, candidates cannot render the alternative they represent more appealing to voters. This result already rules out any possible reversals in the conclusions of Theorem 1. But we can also show that in this setting, $\mathrm{PE}$ admit electoral equilibria with an interior equilibrium in campaign spending. Thus, Theorem 1 holds unchanged. ${ }^{16}$

Remark 2 In the selection+choice model, the nonideological appeal of candidates (inherited or acquired) is larger in majoritarian than in proportional elections (strictly larger for a nontrivial set of parameters).

\footnotetext{
${ }^{16}$ To show this, we exploit the fact that the continuation games of the selection+choice model are a generalization of the choice model, allowing heterogeneous initial conditions $\theta_{k}^{s}$. Consider a LS profile in the benchmark choice model such that $\theta^{\star}<1$ in which all interior candidates earn zero rents (this can be supported as an equilibrium, see Iaryczower and Mattozzi 2008, 2012). Fixing parameters, consider a strategy profile in the selection+choice model such that $\theta_{k}^{s}=0$ and $\theta_{k}^{c}=\theta^{*}$ for all interior candidates $k$. It can be shown that for any given $\theta_{-k}, \theta_{k}^{s}+\theta_{k}^{c *}\left(\theta_{k}^{s}\right)$ is increasing in $\theta_{k}^{s}$ (the higher initial "valence" acts as a subsidy in the continuation game). Together with the fact that $c\left(\theta^{s}\right)+\hat{c}\left(\theta^{c}\right)=C\left(\theta^{s}+\theta^{c}\right)$, the zero profit condition implies that no candidate $k^{\prime}$ such that $\theta_{k^{\prime}}^{s}+\theta_{k^{\prime}}^{c}=1$ has an incentive to run for office. Entry of candidates with different ideologies are ruled out by the same arguments as in the benchmark choice model.
} 
The conclusions regarding the number of candidates do not change throughout.

In conclusion, if candidates are perceived by voters as heterogeneous in nonideological attributes even in the absence of any investments in persuasive campaigning, and these attributes cannot be affected during the campaign, then for some parameters it is possible to find equilibria in which the nonideological appeal of candidates is larger in proportional than in majoritarian elections. However, if candidates need to campaign in order to differentiate themselves in nonideological attributes or if candidates can complement their innate attributes by campaigning, then the nonideological appeal of candidates (inherited and/or acquired) will be higher in majoritarian than in proportional elections.

\section{Conclusion}

In spite of its relevance in modern elections, campaigning has not been systematically integrated in a theory of elections together with the number and ideological position of candidates running for office. This omission could be of no major consequence if the intensity of campaign competition were unrelated to other characteristics of the menu of alternatives available to voters. On the contrary, however, the number of candidates running for office, their ideological differentiation, and the intensity of campaign competition are all naturally intertwined and jointly determined in response to the incentives provided by the electoral system.

In this article, we tackle jointly the effect of alternative electoral systems on the number of candidates running for office, the ideological diversity of their platforms, and the intensity of competition in persuasive campaigning. Our central result is to establish a comparison between proportional and majoritarian electoral systems. First, we show that majoritarian elections induce candidates to campaign more aggressively than proportional elections. In particular, we expect candidates in majoritarian elections to invest more than their counterparts in proportional election systems to reduce voters' uncertainty about the policy they will implement once in office, to hire higher-quality staff, and generically to invest more in researching, drafting, and communicating appropriate policy responses to current events. Second, we show that in all equilibria in which candidates are ideologically differentiated, the number of candidates running for office is larger in proportional than in majoritarian elections, where exactly two candidates run. Third, we show that the ideological differentiation between candidates running for office can in general be larger or smaller in proportional than in majoritarian elections: while electoral equilibrium in proportional elections bounds the minimum and maximum degree of differentiation between candidates, this is not the case in majoritarian elections, where both full centrism and complete polarization are possible.

We show that our main comparison also holds under alternative specifications of the policy function mapping elected representatives to policy outcomes and in electoral systems with multiple electoral districts. We also consider a variant of the main model in which candidates are perceived by voters as heterogeneous in nonideological attributes even in the absence of any investments in persuasive campaigning. We show that if these attributes cannot be affected during the campaign, then for some parameters it is possible to find equilibria in which the nonideological appeal of candidates is larger in proportional than in majoritarian elections. However, if candidates can complement their innate attributes by campaigning, then the nonideological appeal of candidates (inherited and/or acquired) will be higher in majoritarian than in proportional elections, as in the case of the benchmark model.

The reality of the political systems that we are studying is undoubtedly more complex than what our model suggests. Officials elected in majoritarian elections must sometimes bargain with members of a second chamber or face constraints brought by issues as diverse as federalism, the courts, lobbies, and the limits to the scope of governmental action. Likewise, the process of government formation in parliamentary democracies implies that the power of individual parties to affect government policy depends on a complex dynamic of a complex game. Our goal here is not to deny any of these forces and mechanisms but to simplify this complex reality in order to focus on the key aspects of the interaction between entry, ideology, and campaign competition in a productive environment. ${ }^{17}$

Many interesting aspects remain to be addressed and are left for future research. We believe that the simplicity and flexibility of the framework introduced in this article will facilitate this progress.

\footnotetext{
${ }^{17}$ See Austen-Smith and Banks (1988) and Schofield and Sened (2006) for a more elaborate focus on the process of policy formation among elected parties.
} 


\section{Acknowledgments}

We thank Juan Carrillo, Federico Echenique, Zucchero Fornaciari, Daniela Iorio, Alessandro Lizzeri, Matthias Messner, Jean-Laurent Rosenthal, the editors and three anonymous reviewers. We also thank numerous seminar participants at various institutions for helpful comments to previous versions of this article. An earlier version was circulated under the title "Ideology and Competence in Alternative Electoral Systems."

\section{References}

Aragones, E., and T. R. Palfrey. 2002. "Mixed Equilibrium in a Downsian Model with a Favored Candidate." Iournal of Economic Theory 103 (1): 131-61.

Ashworth, S., and E. Bueno de Mesquita, 2009. "Elections with Platform and Valence Competition." Games and Economic Behavior 67 (1): 191-216.

Austen-Smith, D. 2000. "Redistributing Income under Proportional Representation." Iournal of Political Economy 108 (6): 1235-69.

Austen-Smith, D., and J. S. Banks. 1988. "Elections, Coalitions, and Legislative Outcomes." American Political Science Review 82 (2): 405-22.

Baron, D. P., and D. Diermeier. 2001: "Elections, Governmens and Parliaments in Proportional Representation Systems." The Quarterly Journal of Economics 116 (3): 933-67.

Besley, T., and S. Coate. 1997. "An Economic Model of Representative Democracy." The Ouarterlv Journal of Economics 112 (1): 85-114.

Carrillo, J. D., and M. Castanheira. 2008. "Information and Strategic Political Polarization." The Economic Journal 118 (530): 845-74.

Coleman, J. J., and P. F. Manna. 2000. "Congressional Campaign Spending and the Quality of Democracy." Lournal of Politics 62 (3): 757-89.

Cox, G. 1997. Making Votes Count. Cambridge: Cambridge University Press.

Erikson, R., and T. Palfrey. 2000. "Equilibria in Campaign Spending Games: Theory and Data." American Political Science Review 94 (3): 595-609.

Eyster, E., and T. Kittsteiner. 2007. "Party Platforms in Electoral Competition with Heterogeneous Constituencies." Theoretical Economics 2 (1): 41-70.

Feddersen, T. 1992. “A Voting Model Implying Duverger's Law and Positive Turnout." American Journal of Political Science 36 (4): 938-62.

Feddersen, T., I. Sened, and S. Wright. 1990. "Rational Voting and Candidate Entry under Plurality Rule." American Journal of Political Science 34 (4): 1005-16.

Gerber, A. S. 1998. "Estimating the Effect of Campaign Spending on Senate Election Outcomes Using Instrumental Variables." American Political Science Review 92 (2): 401-11.

Green, D. P., and J. S. Krasno. 1988. "Salvation for the Spendthrift Incumbent: Reestimating the Effects of Campaign Spending in House Elections." American Journal of Political Science 32 (4): 884-907.
Greenberg, J., and K. Shepsle. 1987. "The Effect of Electoral Rewards in Multiparty Competition with Entry." American Political Science Review 81 (2): 525-38.

Groseclose, T. 2001. "A Model of Candidate Location when one Candidate has a Valence Advantage." American Journal of Political Science 45 (9): 862-86.

Grossman, G. M., and E. Helpman. 1996. "Electoral Competition and Special Interest Politics." The Review of Economic Studies 63 (2): 265-86.

Herrera, H., D. K. Levine, and C. Martinelli. 2008. "Policy Platforms, Campaign Spending and Voter Participation." Lournal of Public Economics 92 (3-4): 501-13.

Iaryczower, M., and A. Mattozzi. 2008. "Many Enemies, Much Honor? On the Competitiveness of Elections in Proportional Representation Systems." In Aragones, E., Bevia, The Political Economy of Democracy, ed. E. Aragones, C. Bevia, and N. Schofield. Bilbao, Spain: Fundacion BBVA, 2008.

Iaryczaver, M., and A. Mattozzi. 2012. "The Pro-Competitive Effect of Campaign Limits in Non-Majoritarian Elections." Economic Theory 49 (3): 591-19.

Kartik, N., and P. McAfee. 2007. "Signaling Character in Electoral Competition." American Economic Review 97 (3): 852-70.

Lizzeri, A., and N. Persico. 2001. "The Provision of Public Goods under Alternative Electoral Incentives." American Economic Review 91 (1): 225-39.

Meirowitz, A. 2008. "Electoral Contests, Incumbency Advantages and Campaign Finance, "Iournal of Politics 70 (3): 681-99.

Morelli, M. 2004. "Party Formation and Policy Outcomes under Different Electoral Systems." Review of Economic Studies 71 (3): 829-53.

Myerson, R. B. 1993a. " Incentives to Cultivate Favored Minorities Under Alternative Electoral Systems." American Political Science Review. 87 (4): 856-69.

Myerson, R. B. 1993b. "Effectiveness of Electoral Systems for Reducing Government Corruption: A GameTheoretic Analysis." Games and Economic Behavior 5 (1): 118-32.

Osborne, M. J., and A. Slivinski. 1996. "A Model of Political Competition with Citizen-Candidates." The Quarterly Journal of Economic 111 (1): 65-96.

Palfrey, T. R. 1984. "Spatial Equilibrium with Entry." Review of Economic Studies 51 (1): 139-56.

Palfrey, T. R. 1989. "A Mathematical Proof of Duverger's Law." In Models of Strategic Choice in Politics, ed. Peter C. Ordeshook. Ann Arbor: University of Michigan Press, 69-91.

Patty, J. W., J. Snyder, and M. Ting. 2009. “Two's Company, Three's an Equilibrium: Strategic Voting and Multicandidate Elections." Quarterly Journal of Political Science 4 (3): 251-78.

Persico, N., and N. Sahuguet. 2006. "Campaign Spending Regulation in a Model of Redistributive Politics." Economic Theory 28 (1): 95-124.

Persson, T., G. Roland, and G. Tabellini. 2003. "How Do Electoral Rules Shape Party Structures, Government Coalitions and Economic Policies." Department of Economics, University of California Berkeley.

Persson, T., G. Tabellini, and F. Trebbi. 2006. "Electoral Rules and Corruption." Iournal of the European Economic Association 1 (4): 958-89. 
Schofield, N. 2004. "Equilibrium in the Spatial Valence Model of Politics." Iournal of Theoretical Politics 16 (4): 447-81.

Schofield, N., and I. Sened. 2006. Multiparty Democracy: Elections and Legislative Politics. Cambridge: Cambridge University Press.

Stokes, D. E. 1963. "Spatial Models of Party Competition." American Political Science Review 57 (2): 368-77.
Stratmann, T. 2009. "How Prices Matter in Politics: The Returns to Campaign Advertising." Public Choice 140 (3): 357-77.

Matias Iaryczower, Assistant Professor of Politics, Princeton University, Princeton, NJ 08544.

Andrea Mattozzi, Professor of Economics at EUI and MOVE Research Fellow, Florence, I-50133. 